Review

\title{
Antibiotics for cancer treatment: A double-edged sword
}

\author{
Yuan Gao1,2, Qingyao Shang1,2, Wenyu Li1 ${ }^{1,2}$, Wenxuan Guo ${ }^{1}$, Alexander Stojadinovic ${ }^{3}$, Ciaran Mannion ${ }^{3,4}$, \\ Yan-gao $\operatorname{Man}^{3}$ and Tingtao Chen ${ }^{1 \times}$ \\ 1. National Engineering Research Center for Bioengineering Drugs and the Technologies, Institute of Translational Medicine, Nanchang University, 1299 \\ Xuefu Road, Honggu District, Nanchang, 330031 People's Republic of China. \\ 2. Queen Mary School, Nanchang University, Nanchang, Jiangxi 330031, PR China. \\ 3. Department of Pathology, Hackensack University Medical Center, 30 Prospec Avenue, Hackensack, NJ 07601, USA \\ 4. Department of Pathology, Hackensack Meridian School of Medicine at Seton Hall University, 340 Kingsland Street, Nutley, NJ 07110, USA. \\ $\triangle$ Corresponding author: Dr. Tingtao Chen Institute of Translational Medicine, Nanchang University, Nanchang, Jiangxi 330031, PR China; E-mail: \\ chentingtao1984@163.com; Tel: +86-791-83827170, or Dr. Yan-gao Man, Man Department of Pathology, Hackensack Meridian Health-Hackensack University \\ Medical Center, NJ, USA; e-mail: yanmann@aol.com.
}

(1) The author(s). This is an open access article distributed under the terms of the Creative Commons Attribution License (https://creativecommons.org/licenses/by/4.0/). See http://ivyspring.com/terms for full terms and conditions.

Received: 2020.04.27; Accepted: 2020.06.14; Published: 2020.06.28

\begin{abstract}
Various antibiotics have been used in the treatment of cancers, via their anti-proliferative, pro-apoptotic and anti-epithelial-mesenchymal-transition (EMT) capabilities. However, increasingly studies have indicated that antibiotics may also induce cancer generation by disrupting intestinal microbiota, which further promotes chronic inflammation, alters normal tissue metabolism, leads to genotoxicity and weakens the immune response to bacterial malnutrition, thereby adversely impacting cancer treatment. Despite the advent of high-throughput sequencing technology in recent years, the potential adverse effects of antibiotics on cancer treatments via causing microbial imbalance has been largely ignored. In this review, we discuss the double-edged sword of antibiotics in the field of cancer treatments, explore their potential mechanisms and provide solutions to reduce the potential negative effects of antibiotics.
\end{abstract}

Key words: Antibiotics; Cancer; Intestinal microbiota disorder; Cancer therapy

\section{Introduction}

Cancer is a common and frequently-occurring disease which seriously endangers human health. According to the view of modern cell biology, its basic mechanisms are abnormal growth and migration of cells with uncontrolled cell cycle, continuous selfrenewal and reproduction of cancer stem cells [1]. More than eight million people die of cancers each year, which places severe burden on economic and social development around the world [1].

Nowadays, weapons to fight cancers include surgery, radiotherapy, chemotherapy, immunotherapy and targeted therapy [2]. Surgery alone has been offering a cure for cancers for centuries. With advancement in modern therapy, approximately $50 \%$ of all cancer patients are treated with radiotherapy because of the relative light damage to the body [2]. However, surgery and radiation therapy can only be used to treat malignant cancers, which are confined locally to a particular organ [2]. With the paradigm shift in our understanding of cancer as a systemic disease, chemotherapy and targeted therapy, which are used to kill cancer cells that have metastasized to distant sites in the body, have assumed increasingly larger role in cancer treatment and the challenges to patient care poised by acquired resistance and/or the the genotoxic nature of such treatments have started to come more sharply into focus [3].

Antibiotics refer to the secondary metabolites produced by microorganisms (including bacteria, fungi, actinomycetes) or higher animals and plants in the course of life that have anti-pathogen or other activities and can interfere with the development of other living cells [4]. According to research findings, antibiotics can promote cancer apoptosis, inhibit cancer growth and prevent cancer metastasis. For these reasons, antibiotics are increasingly being used to assist in the treatment of cancers [5]. However, the 
administration of antibiotics can also indiscriminately kill advantageous bacterial groups, such as Lactobacillus and Bifidobacterium, in addition to the pathogenic bacteria [6]. The intestinal microbiome plays a very important role in cancer treatment. Thus, the use of antibiotics not only leads to disruption of the microbiome, but also reduces the body's immune capacity and promotes inflammation, which ultimately may impact and reduce the effect of cancer treatment [7].

Given the double-edged sword of antibiotics in the development of cancer therapy, this review aims to explore the role of antibiotics in cancer development and treatment, hoping to provide a better direction and method for the use of antibiotics in the treatment of cancer diseases in the future.

\section{Definition and Classification of Anticancer Antibiotics}

Antibiotic is a kind of medicine that can kill or inhibit the growth of bacteria. It generally refers to the substances produced by bacteria, molds or other microorganisms in the process of life [4]. The first breakthrough in antibiotics dates back to 1929 by Alexander Fleming. As the years pass, the antibiotics commonly used at present mainly include $\beta \sim$ lactams, aminoglycans, tetracycline, chloramphenicol, macrocyclic lipids, lincomines, polypeptides, rifamycin and quinolones [4]. Their bacteriostatic or bactericidal effects mainly include four major mechanisms, which are inhibition of bacterial cell wall synthesis, enhancement of bacterial cell membrane permeability, interference with bacterial protein synthesis and inhibition of bacterial nucleic acid replication and transcription [4]. Their bacteriostatic or bactericidal effects mainly rely on four major mechanisms shown in Figure 1, which are inhibition of bacterial cell wall synthesis, enhancement of bacterial cell membrane permeability, interference with bacterial protein synthesis and inhibition of bacterial nucleic acid replication and transcription [8].

Anticancer antibiotics are chemicals produced by microorganisms with anticancer activity [9]. They are mainly peptides and anthraquinones, with obvious and effective inhibitory effect on the uncontrolled proliferation, aggressive growth and metastasis of malignant cancers. The classification of anticancer antibiotics mainly includes anthracyclines, mitomycin, bleomycin, actinomycin, guanorycin and endiyne $[9,10]$. In addition, their anticancer effects are also very complex and effective. Anthracyclines anticancer antibiotics mainly include daunorubicin, doxorubicin, epirubicin and mitoxantrone. Doxorubicin has a broad clinical anticancer spectrum. It is generally used for solid cancers, and is effective against malignant lymphoma, breast cancer, lung cancer, liver cancer, gastric cancer and soft tissue sarcoma, but can also have a good effect on acute leukemia [11, 12]. Both daunorubicin and doxorubicin have an anthracyclic plane, which can be inserted between DNA base pairs and tightly bound to DNA, becoming an obstacle of DNA spatial structure, thus inhibiting DNA and DNA-dependent RNA synthesis, and can selectively act on purine nucleosides [13]. At the same time, with the effects of cytotoxicity, daunorubicin and doxorubicin can also inhibit the activity of nuclear topoisomerase, interfere with the DNA fracture-reconnection reaction caused by topoisomerase, leading to DNA double strand break, as well as DNA single strand break [14]. Mitomycin has anticancer effect on a variety of cancers, also works as a non-specific drug in cell cycle [15]. It has a broad anticancer spectrum and a fast curative effect, however, its therapeutic index is low and its toxicity is high. When mitomycin bind to DNA, most of them only act on one strand, and some of them form a cross-link to block the disassembly of DNA double strand, thus destroying the stable double helix conformation of DNA to some extent [15, 16]. Bleomycin was the first glycopeptide antibiotic isolated from Streptomyces rotundus by metzibinoff of the Japanese institute of microbiology and chemistry [17]. It can effectively inhibit the synthesis of DNA, causing the break of single and double strands of DNA [17]. Actinomycin is a class of antibiotics containing cyclic peptides, which can be embedded in the groove of the DNA double helix to form a complex with DNA, thereby inhibiting the function of RNA polymerase and ultimately inhibiting RNA synthesis [18]. Defuminomycin can form stable complexes with DNA and interfere with DNA template, thus selectively inhibiting RNA synthesis. The effect of endiyne anticancer antibiotics is similar to that of actinomycin anticancer antibiotics.

\section{The Mechanisms and Rationale for Cancer treatment with Antibiotics}

\section{Proven and potential cellular mechanism for cancer treatment with antibiotics}

With the rapid development of modern science and technology, especially biomedicine in the 20th century, the understanding of cancer etiology has reached the cellular and molecular levels. According to modern cell biology, cancers are a class of cellular diseases characterized by abnormal cell growth. Since each cancer originates from a single cell, the malignant behavior of cancer cells is transmitted to their progeny through cell proliferation, and cancers are also diseases that involve changes in the structure 
and function of genetic material (DNA). Meanwhile, the invasive growth and metastasis of cancer cells are also the promotion factors of the occurrence and development of cancer. Anticancer class antibiotics are one of the most important classes of antibiotics, which have their specific inhibitory effects on cancers
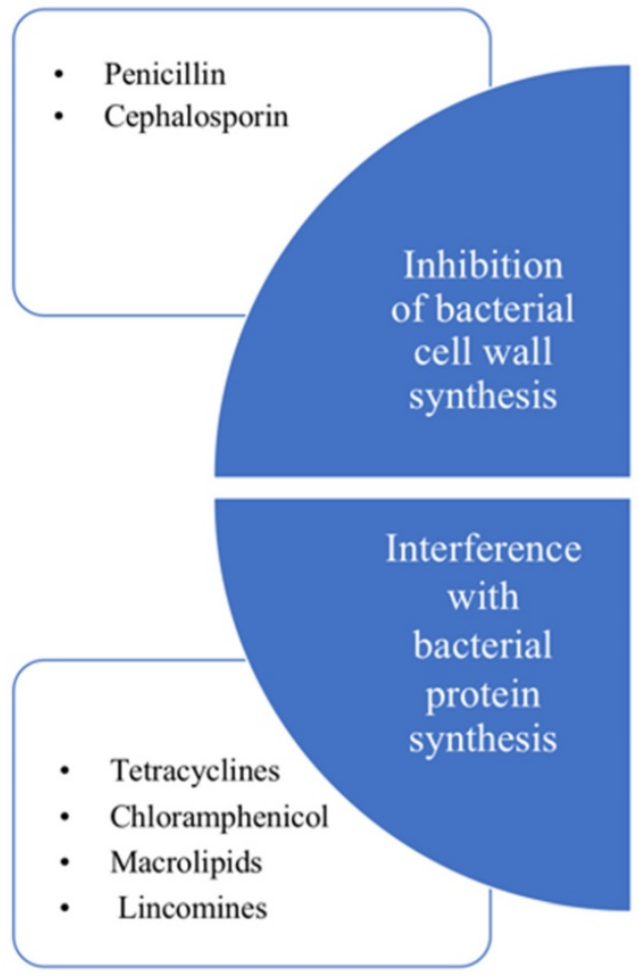

[19]. It can be shown in Table 2 and Figure 2 that anticancer antibiotics have anticancer effects principally through three mechanisms, which are anti-proliferative, pro-apoptotic and anti-epithelialmesenchymal-transition (EMT).

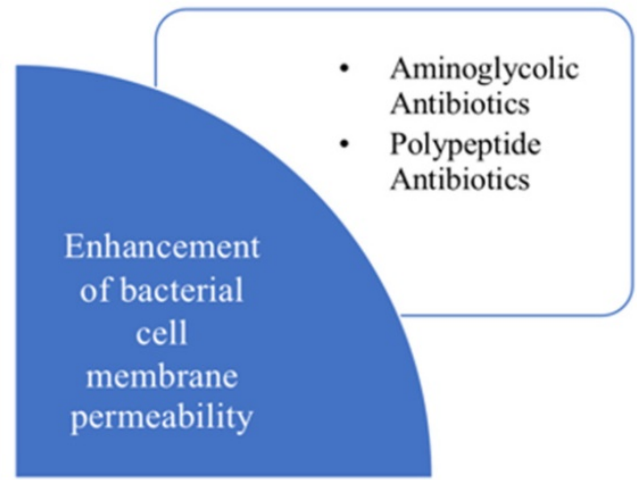

Inhibition of

bacterial

nucleic acid

replication

and

transcription

- Dichloroacridine

- Quinolones

Figure 1. Classification and antibacterial mechanism of antibiotics. The four major mechanisms: inhibition of bacterial cell wall synthesis, enhancement of bacterial cell membrane permeability, interference with bacterial protein synthesis and inhibition of bacterial nucleic acid replication and transcription.

Table 1. Classification of anticancer antibiotics

\begin{tabular}{|c|c|c|c|}
\hline & Antibiotics & Mechanism of action & Clinical application \\
\hline \multirow[t]{5}{*}{ Anthracycline } & Daunorubicin & $\begin{array}{l}\text { Insert into the base pairs of DNA and lead to the obstruction of the spatial } \\
\text { structure of DNA }\end{array}$ & $\begin{array}{l}\text { Acute myeloblastic leukemia } \\
\text { Acute lymphocytic leukemia; }\end{array}$ \\
\hline & Adriamycin & $\begin{array}{l}\text { Insert of the double helix into the DNA and inhibit the action of the DNA } \\
\text { polymerase }\end{array}$ & $\begin{array}{l}\text { Malignant lymphoma } \\
\text { Breast cancer } \\
\text { Lung cancer; }\end{array}$ \\
\hline & Epirubicin & Interfere with the transcription process and prevent mRNA formation & $\begin{array}{l}\text { Leukemia } \\
\text { Malignant lymphoma } \\
\text { Myeloma; }\end{array}$ \\
\hline & Mitoxantone & $\begin{array}{l}\text { Insert of the double helix into the DNA and inhibit the action of the DNA } \\
\text { polymerase }\end{array}$ & $\begin{array}{l}\text { Malignant lymphoma } \\
\text { Breast cancer } \\
\text { Acute leukemia; }\end{array}$ \\
\hline & Pirarubicin & $\begin{array}{l}\text { Insert of the double helix into the DNA and inhibit the action of the DNA } \\
\text { polymerase }\end{array}$ & Lung cancer; \\
\hline \multirow[t]{5}{*}{ None anthracyclines } & Mitomycins & Bind to the DNA and prevent the DNA from breaking apart & $\begin{array}{l}\text { Digestive tract carcer } \\
\text { Cervical cancer; }\end{array}$ \\
\hline & Bleomycins & Cause the DNA to double strand break & $\begin{array}{l}\text { Esophagus cancer } \\
\text { Cervical cancer } \\
\text { Lung cancer; }\end{array}$ \\
\hline & Pingyangmycin & Cause the DNA to double strand break & Prostatic cancer; \\
\hline & Actinomycins & Inhibit the function of RNA polymerase and synthesis of mRNA & $\begin{array}{l}\text { Neuroblastoma } \\
\text { Nephroblastoma; }\end{array}$ \\
\hline & Mithramycin & Inhibit the synthesis of DNA and RNA & $\begin{array}{l}\text { Encephalophyma } \\
\text { Malignant melanoma; }\end{array}$ \\
\hline
\end{tabular}




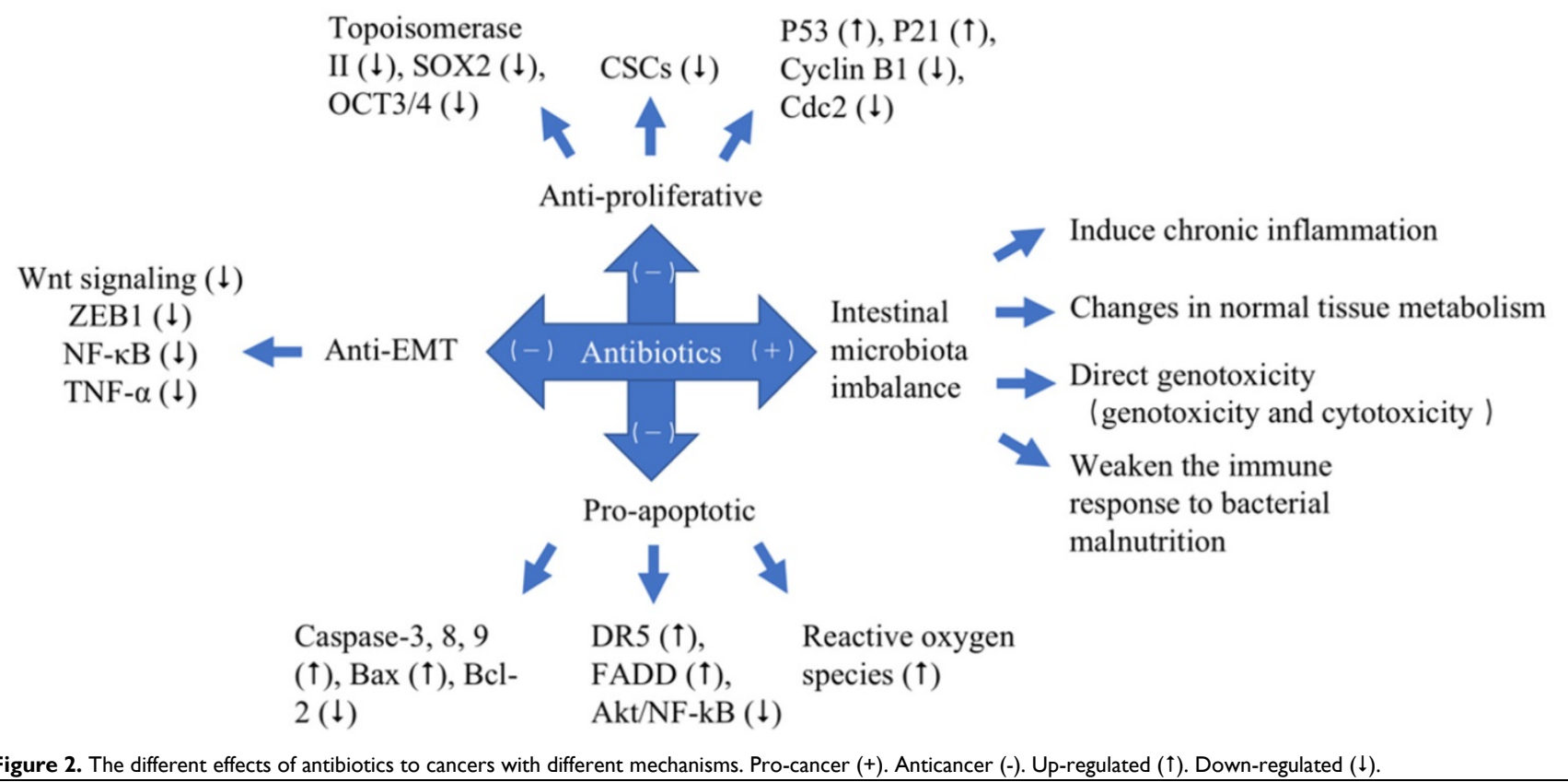

Table 2. Anticancer activity of antibiotics with their mechanisms of action*

\begin{tabular}{|c|c|c|c|c|c|}
\hline S.No. & Antibiotics & Type of Cancer Cell & Mode of Anticancer Activity & Mechanism of Action & Ref \\
\hline \multirow[t]{7}{*}{1} & \multirow[t]{7}{*}{ Salinomycin } & - & Anti-proliferative & Kills CSCs & [54] \\
\hline & & Lung cancer cells & Suppression of self-renewal abilities & $\begin{array}{l}\text { Inhibit the spheroid-forming capability of } \\
\text { non-small cell lung CSCs }\end{array}$ & [20] \\
\hline & & & Anti-proliferative & $\begin{array}{l}\text { mRNA expression of SOX2 }(\downarrow), \text { OCT3/4 } \\
(\downarrow)\end{array}$ & [55] \\
\hline & & Colon cancer cells & Pro-apoptotic & $\begin{array}{l}\text { mRNA and Protein expression levels of } \\
\text { caspase- } 3(\uparrow) \text {, caspase- } 8(\uparrow) \text {, caspase- } 9(\uparrow) \\
\operatorname{Bax}(\uparrow), \text { Bcl- } 2(\downarrow)\end{array}$ & [21] \\
\hline & & Ovarian cancer cell & Pro-apoptotic & $\begin{array}{l}\text { The expression of DR5 }(\uparrow), \text { FADD }(\uparrow), \\
\text { Akt/NF-kB }(\downarrow)\end{array}$ & {$[56,57]$} \\
\hline & & Colorectal and Prostate cancer cells & Pro-apoptotic & Accumulation of reactive oxygen species & [56] \\
\hline & & Mantle cell lymphoma (MCL) cells & $\begin{array}{l}\text { Anti-Epithelial-Mesenchymal- } \\
\text { transition (EMT) }\end{array}$ & Wnt signaling $(\downarrow)$, ZEB1 $(\downarrow)$ & {$[22]$} \\
\hline \multirow[t]{4}{*}{2} & \multirow[t]{4}{*}{ Ciprofloxacin } & Melanoma cells & S-phase arrest & Topoisomerase II inhibition & {$[33,34]$} \\
\hline & & Human non-small cell lung cancer & G2/M checkpoint arrest & $\begin{array}{l}\text { The expression of p53 }(\uparrow), \text { p } 21(\uparrow) \text {, cyclin } \\
\text { B1 }(\downarrow), \text { Cdc2 }(\downarrow)\end{array}$ & {$[35,36]$} \\
\hline & & & $\begin{array}{l}\text { Disruption of mitochondrial } \\
\text { membrane potential }\end{array}$ & $\begin{array}{l}\text { Oligonucleosomal DNA fragmentation, } \\
\text { p53 }(\uparrow)\end{array}$ & [33] \\
\hline & & $\begin{array}{l}\text { Human triple-negative breast cancer } \\
\text { MDA-MB-231 cells }\end{array}$ & $\begin{array}{l}\text { Disruption of mitochondrial } \\
\text { membrane potential }\end{array}$ & Bax/Bcl-2-dependent pathway $(\uparrow)$ & {$[34]$} \\
\hline 3 & Gemifloxacin & Human breast adenocarcinoma cells & $\begin{array}{l}\text { Inhibit the Snail expression, the } \\
\text { localization of Snail in cell nuclei }(\downarrow)\end{array}$ & The activation of NF-kB $(\downarrow)$, TNF- $\alpha(\downarrow)$ & [43] \\
\hline \multirow[t]{3}{*}{4} & \multirow[t]{3}{*}{ Doxorubicin } & - & $\begin{array}{l}\text { Binds to small grooves in DNA } \\
\text { fragments }\end{array}$ & Produces reactive oxygen species (ROS) & [26] \\
\hline & & & Trap topoisomerase II & DNA double-strand breakage, p53 ( $\uparrow$ & {$[27]$} \\
\hline & & & $\begin{array}{l}\text { Activation of various molecular } \\
\text { signals from AMPK }(\uparrow)\end{array}$ & Bcl-2/Bax ratio $(\downarrow)$ & {$[27]$} \\
\hline \multirow[t]{2}{*}{5} & \multirow[t]{2}{*}{ Mitomycin } & - & G1-phase and early S-phase arrest & The synthesis of RNA and protein $(\downarrow)$ & {$[47]$} \\
\hline & & & $\begin{array}{l}\text { Form double or intra-strand } \\
\text { cross-links DNA }\end{array}$ & Replication and Synthesis of DNA $(\downarrow)$ & {$[48]$} \\
\hline
\end{tabular}

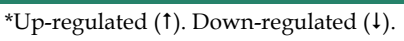

\section{Proven and potential molecular mechanism for cancer treatment with antibiotics}

On the one hand, anticancer antibiotics can kill cells in the whole proliferation cycle, even G0 phase cells, thereby achieving the anti-proliferation ability of cancer cells by affecting the cell cycle, such an example with cyclinenon-specific drugs (CCNSC) [20]. On the other hand, anticancer antibiotics can promote apoptosis of cancer cells by targeting apoptotic gene B cell lymphoma-2 (Bcl-2), apoptotic pro-Bcl-2-associated $\times$ (Bax), caspase-3/8/9 and cancer suppressor gene $\mathrm{P} 53$, thereby impacting cancer 
cell apoptosis in patients [21]. In addition, anticancer antibiotics can be used as regulatory agents of EMT to inhibit the metastasis of cancer cells and play an anti-metastasis role [22]. For example, ciprofloxacin has pro-apoptosis ability while salinomycin can inhibit proliferation and EMT in the development of cancers [23].

Many experts have found that, in particular, cancers tend to be more sensitive to emerging classes of anticancer antibiotics that they have never been exposed to before and that these agents are more effective in inhibiting cancers than those to which the cancer patients have previously been exposed. From the initial anticancer antibiotics such as doxorubicin, epirubicin and mitomycin to the anticancer antibiotics adriamycin, salinomycin and fluoroquinolones discovered in the latest research, the treatment of antibiotics for cancer has become increasingly important.

\section{The Specific applications of Antibiotics for Cancer treatment}

\section{Adriamycin}

Adriamycin is an effective and essential anticancer drug, in particular serving as an indispensable therapeutic ingredient for many childhood cancer patients [24]. It is one of the most commonly used anthracyclines in adults and children. The promycin adriamycin was first isolated from the Streptomyces variety. Caesius was used as an antibiotic in the 1950s [25]. It was not until the 1960s that the drug was first used as a chemotherapeutic [25]. To date, more than 2,000 analogues have been developed, but only a few antibiotics have been approved by the FDA for clinical use [24].

Despite its many functions, doxorubicin is known as a DNA implant and produces reactive oxygen species (ROS) through several different cellular mechanisms [26]. DOX electrostatically binds to small grooves in DNA fragments [26]. In addition to interfering with the synthesis of DNA and macromolecules, adriamycin can also trap topoisomerase II in the normal enzyme activity of topoenzyme II, resulting in DNA double-strand breakage [27]. The immediate consequence of the exposure is the up-regulation of $\mathrm{p} 53$, a reaction to DNA damage that ultimately leads to programmed cell death. Adriamycin is known to bind to DNArelated enzymes, insert DNA base pairs, and target multiple molecular targets to produce a range of cytotoxic effects [26]. For example, it induces activation of various molecular signals from amp-activated protein kinase induces apoptosis (AMPK), which affects the Bcl-2/Bax pathway. By changing the $\mathrm{Bcl}-2 / \mathrm{Bax}$ ratio, the downstream activation of different cystatin proteins can occur, leading to apoptosis [26]. Its main role is to inhibit topoisomerases I and II and insert them into DNA to interfere with their helices, eventually inducing programmed cell death [26].

\section{Bleomycin}

Bleomycin is an antibiotic that can be embedded in DNA with iron complexes, causing single-strand and double-strand breaks in DNA to have antibacterial effects [28]. In recent years, bleomycin has been used as an effective clinical anticancer drug to treat germ cell cancers and lymphomas as well as squamous cell carcinoma [28]. Bleomycin can bind to DNA through its amino terminal peptide, and in the case of oxygen and iron, form DNA-Fe-bleomycin complex, which activates to produce free radicals (hydroxyl radicals) [28]. Unfortunately, the development of pulmonary fibrosis has seriously hampered the therapeutic effect of bleomycin. However, the mechanism of pulmonary fibrosis induced by bleomycin, especially the molecular targets of bleomycin, is still unknown.

\section{Ciprofloxacin}

Fluoroquinolones are broad-spectrum synthetic antibiotics that inhibit the synthesis of bacterial DNA [29]. Despite their accidental discovery, they are the largest class of antimicrobials in use in the world today. These drugs are widely used in clinical practice to treat urinary, respiratory and gastrointestinal infections, bone, skin or soft tissue infections, and eye diseases [29]. They also showed immunoregulatory effects by regulating cytokine production, antiinflammatory responses, and protection against LPSinduced liver injury [30]. The anticancer potential of fluoroquinolones is being studied in a wide range of modules.

Ciprofloxacin is a second-generation fluoroquinolone that is particularly effective against gramnegative bacilli, including Pseudomonas aeruginosa [31]. The drug has a high bioavailability and a large distribution [31]. Ciprofloxacin is widely used in respiratory, urinary and gastrointestinal infections due to its good pharmacokinetic properties and capacity to achieve higher concentrations in tissues than in plasma [32]. The anticancer activity of Ciprofloxacin has been demonstrated in human and animal cancer cell lines in vitro, such as human bladder cancer cell lines, human colorectal cell lines, hamster ovarian cancer cell lines, and human hepatocellular carcinoma [33, 34]. Artur Beberok and Dorota Wrzesniok et al. have shown that the incubation period would be extended to $48 \mathrm{~h}$ and $72 \mathrm{~h}$ 
in low concentration $(0.01 \mathrm{mM}$ and $0.1 \mathrm{mM})$ of ciprofloxacin, and that melanoma cells would appear stagnation of $S$ phase of the cycle by cell fluorescence image analysis through mechanisms associated with topoisomerase II inhibition [33, 34]. In contrast, Kloskowski et al. demonstrated that ciprofloxacin caused cell stagnation at the G2/M checkpoint in human non-small cell lung cancer [35]. At the same time, Hamada H.H. Mohammed et al. showed that derivatives of ciprofloxacin could increase the expression of p53 and p21 and decrease the expression of cyclin B1 and Cdc2 proteins which were an important protein to modulate cell cycle of G2/M in human non-small cell lung cancer cells without any effect on the same proteins expression in other normal cells, which showed dose dependent G2/M arrest in human non-small cell lung cancer cells by flow cytometric analysis [36]. Taken together, derivatives of ciprofloxacin induced G2/M phase arrest via p53/p21 dependent pathway and expression of cyclin B1 and Cdc2 proteins. So, ciprofloxacin can exert antiproliferative effect by regulating the cell cycle process.

Today, fluoroquinolone in promoting the role of cancer cells apoptosis is more and more attention. Artur Beberok et al in 2017 showed that ciprofloxacin induced DNA fragmentation in oligonucleosomes at the highest concentration $(1.0 \mathrm{mM})$ (the alleged presence of sub-g1 fragments) strongly suggesting the induction of apoptosis by mitochondrial dependent pathways, such as disruption of mitochondrial membrane potential [33]. One year later, Artur Beberok et al reported that cipfloxacin treatment stimulated the loss of the mitochondrial transmembrane potential via the Bax/Bcl-2dependent pathway, thus inducing apoptosis in human triple-negative breast cancer MDA-MB-231 cells [34]. Oligonucleosomal DNA fragmentation and the elevation of p53 expression were observed in this study, indicating that this late-apoptotic event may be mediated by the p53-dependent pathway [34].

\section{Dactinomycin}

So far, at least 50 kinds of dactinomycin have been found, and only dactinomycin D and C have clinical application value, which is also known as actinomycin [37]. Dactinomycin D is a polypeptide antibiotic extracted from the nutrient solution of Str. Parvul-lus [38]. Its molecules contain a phenoxy ring structure that connects two allelic cyclic peptide chains [38]. This peptide chain can interact with deoxyguanine of DNA molecule in a specific way, making dactinomycin $\mathrm{D}$ embedded in the groove of DNA double helix, forming complex with DNA, hindering the function of RNA polymerase, inhibiting the synthesis of RNA, especially the synthesis of
mRNA, thus inhibiting the occurrence and development of cancer [37, 38]. Dactinomycin has a narrow anticancer spectrum and is mainly used for nephroblastoma, chorionic epithelial carcinoma, rhabdomyosarcoma and neuroblastoma [37].

\section{Daunorubicin}

In 1957, researchers in Farmitalia's laboratory extracted pilomycin from Streptomycin peucetius in culture [39]. Then, in 1963, Di Marco et al. demonstrated the anticancer effect of daunorubicin in a preclinical trial [40]. At the same time, French scientist Phome-phouleuc et al. isolated the same substance erythrobicin from the culture solution of Streptomycin ceruleorubidus in the laboratory $[39,40]$. A few years later, Chinese scholars obtained the same strain in the soil of Hebei province, extracted the same substance and named it candimycin [39]. Later, all of these similar mycin were uniformly named as daunorubicin. Daunorubicin is a first-line cancer antibiotic, widely used in acute myelogenous leukemia, lymphocytic leukemia and other malignant cancers [39]. It can inhibit cancer growth by chimerism between DNA base pairs of cancer cells and tightly binding to DNA, resulting in the obstruction of DNA spatial structure [39].

\section{Epirubicin}

Epirubicin is a new anthracycline antibiotic that can be embedded directly between DNA nucleobase pairs to interfere with the transcription process and prevent the formation of mRNA, thereby inhibiting the synthesis of DNA and RNA [41]. In addition, it also can inhibit topoisomerase II. Epirubicin, as a cell cycle nonspecific drug, is effective against a variety of transplanted cancers. It is commonly used for the treatment of breast cancer, malignant lymphoma, soft tissue sarcoma, gastric cancer, malignant melanoma, colon cancer, lung cancer, ovarian cancer and so on [41]. But epirubicin has also been shown to inhibit bone marrow, cardiac toxicity, hair loss, mucositis, gastrointestinal tract reactions, high fever, and other adverse reactions [41].

\section{Gemifloxacin}

Gemifloxacin (GMF) is a fluoroquinolone antibiotic that inhibits bacterial DNA gyrase and topoisomerase IV, which not only has antiproliferative and pro-apoptotic effects, but also has an anti-metastatic activity [42]. Tun-Chieh Chen et al. first showed that GMF suppressed the activation of $\mathrm{NF}-\mathrm{KB}$, as well as the cell migration and invasion induced by cancer necrosis factor a (TNF-a) [43]. Cancer cells in which NF-kB is constitutively active are highly metastatic, and inhibition of NF- $\mathrm{kB}$ activity in these cells greatly decreases their invasiveness [43]. 
The transcription factor Snail, one of the target genes of NF- $\mathrm{KB}$, is a key regulatory factor in EMT and cell migration [44]. Its expression is elevated in several cancer types, including breast cancer [44]. Snail transcriptionally suppresses the adherent junction protein, E-cadherin, by binding to E2-box-type elements within its promoter, resulting in EMT [45]. E-cadherin loss and EMT induction have been implicated in the enhancement of metastatic ability and are closely correlated with poor prognosis [45]. Tun-Chieh Chen et al. found that GMF had a significant inhibitory effect on Snail expression, which was consistent with the blockade of NF-kB by GMF [43]. The inhibition of Snail was directly associated with the restoration of E-cadherin. Overexpression of Snail decreased the anti-migration properties and upregulated E-cadherin in human breast adenocarcinoma cells [43]. Their findings also revealed that GMF decreased cancer metastasis by decreasing the localization of Snail in cell nuclei. In conclusion, GMF might be a novel anticancer agent for the prevention and treatment of metastasis in cancer.

\section{Mitomycin}

Mitomycin is an anticancer drug isolated from Actinomycin culture, which is effective in multiple solid cancers and is one of the commonly used cycle non-specific drugs [46]. The structure of benzoquinone, ulatan and ethylene imine form the three effective groups [46]. After the activation of reductase in cells, it acts to depolymerize DNA and antagonize DNA replication. High concentration also inhibits the synthesis of RNA and protein. It is mainly used in late G1 phase and early $S$ phase [47], and also works in acidic and hypoxic conditions [47]. The drug resistance is mainly caused by the decrease of membrane permeability and the decrease of intracellular concentration [47], and degradation accelerates the so-called mutation-selection mechanism. Mitomycin includes three anticancer antibiotics: mitomycin A, mitomycin B, mitomycin C (MMC) [46]. The mechanism of action is through the formation of double or intra-strand cross-links with DNA in order to inhibit DNA replication and synthesis [48]. In addition, MMC-induced addition of oxygen radicals may also contribute to anticancer activity [48]. The adverse reaction of this drug is bone marrow suppression, mainly manifested as decreased platelets [48]. In addition, drug exosmosis can cause tissue ulcer necrosis, medication with doxorubicin [48].

\section{Mitoxantone}

Mitoxantone is a class of anticancer antibiotics, its structure and anticancer effect is similar to doxorubicin [49]. Because Mitoxantone does not have an amino sugar structure, it does not produce free radicals while inhibiting lipid peroxidation, so Mitoxantone is less toxic to the heart [49]. Moreover, mitoxantrone can enter the cell and interact with the mitochondria, thus inhibiting the cancer [49].

\section{Plicamycin}

Plicamycin is also known as brilliant-mycin. Antibiotics extracted from Streptarrryces tanushiensis or S. 684 strain in culture [50]. Plicamycin has a strong inhibitory effect on a variety of cancers, and its mechanism of action is to bind to DNA, inhibit the synthesis of RNA, and act on cell proliferation at each stage [50]. Plicamycin is mainly used in the clinical treatment of testicular embryonal cancer and various malignant cancers caused by hypercalcemia, can also be used for glioma and lymphoma, etc [50]. However, the main side effects are gastrointestinal reactions, bleeding, liver, kidney damage and so on [50].

\section{Salinomycin}

Salinomycin, originally used as an antimicrobial agent to kill bacteria, fungi and parasites and to increase the effectiveness of feed for ruminants [51], was isolated from bacteria of the genus Streptomyces alba and was produced by a tank fermentation technique originally used as an agricultural antimicrobial substitute [51]. This monocarboxylic polyether ionophore is a $751 \mathrm{Da}$ antibiotic, weakly acidic in nature, and acts as an ionophore [51]. As an ionophore with strict selective alkali ions and a strong preference for potassium, it interferes with transmembrane potassium potential [52]. Salinomycin has shown anticancer property, particularly against many types of cancer stem cells (CSCs), and sensitizes multidrug-resistant human cancer cells [52].

CSCs play an important role in cancer survival, proliferation, metastasis and recurrence [53]. In essence, they maintain the vitality of the cancer cell population through self-renewal and unlimited proliferation and enable the metastasis of cancer cells [53]. Therefore, the use of CSC as a target for cancer therapy is very important. Unfortunately, CSCs can remain dormant for long periods of time and have multiple drug-resistant molecules that are insensitive to the physical and chemical factors that kill cancer cells [53]. Gupta et al. first unveiled that salinomycin selectively killed CSCs by high-through screening method, which showed the activity of Salinomycin toward CSCs was 100 folds higher than the comparatively conventional chemotherapeutic drug [54]. At the same time, it was reported that salinomycin could overcome drug resistance in 
human cancer cells [54]. In 2014, Xiao et al reported that salinomycin could significantly inhibit the spheroid-forming capability of non-small cell lung CSCs, reflecting the suppression of self-renewal abilities (20). Years later, Hyun-Gyo Lee, So-Jin Shin et al. showed that salinomycin treatment lessened the expression of sex determining region Y-box 2 (SOX2) and octamer-binding transcription factor $3 / 4$ (OCT3/4) mRNA using reverse transcription polymerase chain reaction and protein levels using western blot analysis [55]. CSCs show that the stemness transcription factors, such as SOX2, OCT3/4 and NANOG, play critical roles in stem cell proliferation and self-renewal, so the decrease in these gene expressions indicates the antiproliferative effect of salinomycin on CSCs [55]. Some mechanisms of salinomycin targeting CSCs in the treatment of cancers are still under research and are not yet clear, but the therapeutic effect on cancers has been demonstrated in recent years.

Over the past decade, there has been a growing recognition that cancer can be treated by promoting apoptosis. In the process of cell apoptosis, caspase-3, caspase-8, caspase-9, Bcl-2 and Bax are vital factors. Caspase-3, caspase-8, caspase- 9 and Bax are proapoptotic genes, which can stimulate the apoptosis of human cancer. In contrast, $\mathrm{Bcl}-2$ is anti-apoptotic gene, which can inhibit the apoptosis of human cancer [23]. Jin Zhou et al in 2013 reported that the mRNA and protein expression levels of caspase-3, caspase-8, caspase- 9 and Bax were effectively up-regulated by salinomycin, while the mRNA and protein expressions of Bcl-2 in cancer cells were downregulated [21]. In their study, they treated colon cancer cells continuously with $5 \mathrm{~mol} / \mathrm{l}$ of cisplatin and successfully obtained cisp-resistant SW620 cells [21]. They then tested specific stem cell markers to see if cisplatin resistant SW620 cells showed dry-like characteristics [21]. To discuss the killing effect of salinomycin on cisplatin resistant SW620 cells, they treated cisplatin resistant SW620 cells and protosw620 cells with a certain concentration of salinomycin and observed changes in cell cycle and apoptosis [21]. A large number of studies have shown that the proportion of Bcl-2/Bax was reduced in different types of cancer cell apoptosis, indicating that salinomycin can promote the apoptosis of cancer cells [21]. In addition, Bidur Parajuli et al also reported in two papers that salinomycin was identified by tetrazolium dye assay to increase the expression of death receptor 5 (DR5) and fas-related proteins with death domain (FADD), and to inhibit Akt/NF-kB induction of cisplatin resistant ovarian cancer cell apoptosis [56, 57]. Furthermore, Jin Zhou et al reported that apoptosis of cisplatin-resistant colorectal and prostate cancer cells is achieved through accumulation of reactive oxygen species [56].

The synergistic action of salinomycin and conventional chemotherapy drugs can inhibit the invasion and migration of cancer cells. The transcription factor ZEB1 is known to promote metastasis of cancer and is highly expressed in primary hairline cell lymphoma (MCL) with well-orchestrated active Wnt signaling [22]. Sanchez-Tillo E et al in 2014 reported that salinomycin could block Wnt signaling and down-regulate ZEB1, thereby increasing the sensitivity of MCL cells to the cytotoxic effects of gemcitabine, cytarabine and adriamycin [58]. Combined with metformin, salinomycin blocked tumor growth factor (TGF)induced EMT and inhibited EMT-induced cell migration in two non-small cell lung cancer (NSCLC) cell lines A549 and HCC4006 [58].

\section{Pro-cancer effect of Antibiotics in the Course of Treatment}

The human gastrointestinal tract is a complex ecosystem, with approximately $10^{11}$ bacteria per gram faeces [59]. These bacteria play an important role in health maintenance and disease development through their involvement in nutrition, pathogenesis and immunology of the host [59]. The equilibrium of the normal microbiome acts as a barrier against colonization by potentially pathogenic microorganisms and against uncontrolled overgrowth of microorganisms already present in the gastric intestinal tract, such as yeasts or Clostridium difficile [60]. Under normal physiological conditions, the balanced state of the microbiome has an immune protective effect, as the cell wall of the dominant bacterial community is the stimulator of certain immune cells. It can activate these cells and stimulate the secretion of antibody, thus improving the body's immunity and resisting the attack of external microbiota [60, 61]. In contrast, intestinal microbiota disorder is an important cause of immune function damage and can trigger a systemic inflammatory response, which can, under certain conditions, induce the occurrence of cancer in patients [60,61].

Multiple lines of modern research suggest that excessive treatment of antibiotics in the treatment of cancer has unintended and, frequently, undesirable consequences. Although it is known that antibiotics have short-term impacts on the human microbiome, recent evidence demonstrates that the impacts of some antibiotics can remain for extended periods of time [62]. Administration of antibiotics causes disturbances in the ecological balance between the host and the microorganisms [62]. Excessive antibiotic treatment will lead to a series of intestinal 
dysbacteriosis, reducing the number of Lactobacillus and Bifidobacterium, as well as the number of harmful bacteria resistant. Researchers have found that the use of antibiotics on premature babies within 7 days of birth significantly lowered the proportion of Enterobacteriaceae and reduced the diversity of the microbiome. To eliminate harmful bacteria, antibiotics can also inadvertently remove the beneficial bacteria, which in turn causes intestinal microbiota imbalance $[60,62]$. In Table 3, these findings outline the possible associations between antibiotic exposure and cancer risk $[60,62]$. Over the years, a series of antibiotics have been tested, targeting cancer cells and inducing cancer occurrence in the treatment of cancer [62]. They may exert their cancer-induced effects via intestinal microbiota imbalance to cause a number of reactions, including effects on inflammatory factors that induce chronic inflammation; changes in normal tissue metabolism; direct genotoxicity, which consists of genotoxicity and cytotoxicity; effecting the efficacy of checkpoint inhibitors and weakening of the immune response to bacterial malnutrition (Figure 2).

\section{Surgical treatment}

Surgical treatment is one of the most effective and common methods for the treatment of cancers. With the exception of malignant cancers of the blood system (such as leukemia, malignant lymphoma), most solid cancers can be treated in the early stages of the disease with surgery. When clinically indicated, the appropriate use of antibiotics can not only prevent or reduce wound infection but can also accelerate wound healing [63]. However, as with any form of trauma, the body's immunity and resistance following surgical intervention will be reduced [63]. The additive use of antibiotics in such a setting can further weaken the body's immunity through intestinal microbiota disorder, potentially increasing the risk of cancer recurrence $[60,62]$.

In 2008, Annamari Kilkkinen et al first reported that the use of penicillin predicted an increased risk of cancer, and the relative risks (RRs) with 95\% confidence intervals ( $95 \%$ CIs) of the most common colon cancer was 1.15 (1.04-1.26) [64]. According to the results, Annamari Kilkkinen supposed that penicillin treatment might promote the development of cancer by affecting intestinal microbiota, which had a major impact on the health of the host [64]. Similarly, studies by Ben Boursi et al in 2015 also showed that through nested case-control studies using a large population database from the United Kingdom, past exposure to penicillin might be associated with a modest increase in colorectal cancer $(\mathrm{CRC})$ risk [65]. Moreover, Ben Boursi postulated that gut microbiota may have served as an important promoter of CRC formation and that, at the same time, the penicillin therapy could have altered the human microbiota [65]. These two independent studies indicate that penicillin affects the composition and function of intestinal flora and immune function.

Under pathological state, the balance of dominant bacterial community and subdominant microbiota is broken, and the intestinal barrier function is damaged. Bacterial structure, function and space position can also be changed, which may eventually cause endogenous infection [60, 62]. Many studies have shown that the abnormal intestinal microbiota count or space position could lead to immune function damage $[60,62]$. In addition, there is strong evidence that indicates that there is cellular immune dysfunction in patients with intestinal microbiota disorder. In terms of humoral immunity, serum immunoglobulin IgA, IgM and IgG levels of patients with intestinal microbiota disorder were lower than those of normal people, indicating that there was also damage of humoral immune function in patients with intestinal microbiota disorder by the use of antibiotics [66].

Table 3. Pro-cancer activity of antibiotics with their mechanisms of action in different therapy methods via intestinal microbiota imbalance*

\begin{tabular}{|c|c|c|c|c|c|}
\hline Therapy methods & Antibiotics & Type of Cancer Cell & Mode of Anticancer Activity & Mechanism of Action & Ref \\
\hline Surgical treatment & Penicillin & Colon cancer & $\begin{array}{l}\text { Abnormal intestinal microbiota } \\
\text { count or space position }\end{array}$ & $\begin{array}{l}\text { Immune function damage, the levels of } \operatorname{Ig} A(\downarrow) \text {, } \\
\operatorname{IgM}(\downarrow), \operatorname{IgG}(\downarrow)\end{array}$ & [65] \\
\hline Radiotherapy & Tetracycline & Breast cancer & Disturb intestinal microbiota & $\begin{array}{l}\text { The conversion of glucosinolates, isoflavone and } \\
\text { glycosides to biologically active agents }(\downarrow)\end{array}$ & {$[68,69]$} \\
\hline \multirow[t]{4}{*}{ Chemotherapy } & Macrolides & Breast cancer & Disorder of intestinal microbiota & $\begin{array}{l}\text { Regulate immune inflammatory factors, induce } \\
\text { chronic inflammation }\end{array}$ & {$[72]$} \\
\hline & $\begin{array}{l}\text { Tetracyclines \& } \\
\text { Macrolides }\end{array}$ & Breast cancer & Disorder of intestinal microbiota & Mitogen-induced T-lymphocyte proliferation ( $(\downarrow)$ & {$[72]$} \\
\hline & Tetracyclines & Breast cancer & Disorder of intestinal microbiota & Production of PGE2 $(\downarrow)$ & {$[71,73]$} \\
\hline & Tetracyclines & - & Disorder of intestinal microbiota & Production of matrix metalloproteinase $(\downarrow)$ & {$[74]$} \\
\hline Immunotherapy & Quinolones & Liver cancers & Disrupt the intestinal microbiota & $\begin{array}{l}\text { Production direct immunotoxicity }(\uparrow) \text {, } \\
\text { genotoxicity }(\uparrow) \text {, cytotoxicity }(\uparrow)\end{array}$ & {$[76,77]$} \\
\hline
\end{tabular}




\section{Radiotherapy}

Cancer radiotherapy is a local treatment of cancers with radiation. About $70 \%$ cancer patients need radiation during cancer treatment, and about $40 \%$ cancers can be cured by radiation [67]. Radiotherapy plays a very important role in the treatment of infantile and vigorous cancer cells, and its role and status in cancer treatment have become increasingly prominent [67]. But while radiation destroys and kills cancer cells, it also destroys surrounding normal tissue cells [67].

Simultaneous treatment with antibiotics and radiotherapy is a common way to fight cancers. Interestingly, some studies have shown that tetracycline-induced breast cancer is also related to changes in intestinal microbiota [68, 69]. Intestinal microbiota converts phytochemicals, such as glucosinolates, isoflavones, and lignans, to compounds that are biologically active in the human body, which may play an inhibitory role at several points in the carcinogenesis pathway and, specifically, may modulate carcinogen and steroid-hormone metabolism, thereby decreasing breast-cancer risk [68, 69]. Adlercreutz $\mathrm{H}$ et al and Shapiro TA et al in 1998 reported that tetracyclines treatment disturbs intestinal microbiota and reduces the conversion of glucosinolates, isoflavone glycosides and lignans to biologically active agents [68, 69]. Low levels of phytochemicals in urine and serum indicate that the body has fewer chemoprophylactic phytochemical metabolites available, possibly leading to an increased risk of breast cancer [68, 69]. Antibiotics have the potential to not only weaken the immune response but can also affect the metabolism of normal tissues through intestinal microbiota disturbances, especially inhibiting the metabolism of plant compounds in normal tissues $[60,62]$. This has a synergistic effect with the destruction of normal tissues in radiotherapy, which greatly reduces the effect of treating cancers during chemotherapy.

\section{Chemotherapy}

Chemotherapy is one of the most effective ways to treat cancer [70], along with surgery and radiotherapy [70]. Surgery and radiotherapy are local treatments that are only effective for cancers at the site of operation, but not for potential metastases or cancers that have already metastasized clinically [63]. In contrast, chemotherapy is a systemic treatment. No matter what route is used for drug administration (oral, intravenous and coelial administration, etc.), chemotherapy drugs will spread throughout most organs and tissues of the body through the blood circulation [70]. Therefore, chemotherapy is the main treatment for some cancers that tend to spread throughout the body and for advanced stage cancers that have already metastasized [70].

The use of a combination of antibiotics and chemicals is increasingly advocated during chemotherapy. However, the chronic inflammation caused by antibiotics in combination therapy by disrupting the intestinal microbiota is also a major obstacle to chemotherapeutic treatment of cancers [71]. At first, it was widely believed by some scientists that tetracycline induced breast cancer by regulating immune inflammatory factors with disorder of intestinal microbiota [71]. In 1979, Thong YH et al first reported in healthy human volunteers that tetracyclines and macrolides inhibited mitogen-induced T-lymphocyte proliferation, which might be an important factor in the association between tetracyclines and breast cancer [72]. In this way, tetracycline inhibition of T-lymphocytes may limit the anticancer response, resulting in increased cancer detriment and metastatic potential in women who already have breast cancer [72]. Decades later, studies by Attur MG et al suggested that tetracyclines increase PGE2 production, which might increase breast-cancer risk through stimulation of aromatase, stimulation of angiogenesis, inhibition of immune surveillance, enhancement of cancerogenic and metastatic potential [73]. Furthermore, Coussens LM et al reported tetracyclines could inhibit production of matrix metalloproteinase, which could induce angiogenesis inhibitors and have apoptotic actions, but it was not cleared for clinical trials [74].

Collectively, these studies indicate that antibiotics administered in the course of cancer chemotherapy treatment can lead to intestinal disorders, affect the immune inflammatory factor and induce the inflammation response through different mechanisms (suppress $\mathrm{T}$ lymphocyte proliferation, increase the generation of PGE2 and inhibit MMPs), which further cause cancer illness aggravation and greatly hinder the effect of chemical therapy (Table 3 ).

\section{Immunotherapy}

Immunotherapy is intended to improve the immunogenicity of cancer, by giving the body a sufficient number of functioning immune cells and related molecules, to inspire and strengthen the body's immune response resistance to cancer, thereby improving the sensitivity of the cancer of the anticancer immunity effect, inducing cancer cellular and molecular specificity and non-specific effect outside the body and achieving the eventual goal of cancer eradication with the aid of molecular biology and cell engineering technology [75]. Cancer cell immunotherapy has been regarded as the fourth treatment method after surgery, radiotherapy and 
chemotherapy, with the inclusion of cytokine therapy, immune cell therapy, gene therapy, molecular targeted therapy and antibody therapy [75].

Kashida et al. first reported that quinolones are not only promoters of liver cancers, but also liver cancer initiators based on in vivo alkaline single-cell gel electrophoresis (comet) test and two-stage studies of liver cancer in mice [76]. Years later, Tadashi Itoh et al chose four old quinolone [NA, PPA, OA and pyrazole and acid (PA)] and four new quinolone [(ENX), according to the north of sand OFLX, head and $\mathrm{CPFX]}$ to study their effects on DNA, and put forward the possibility of the head and CPFX genetic toxicity potential from DNA replication in vitro by its inhibition of topoisomerase II activity, rather than from base adduct formation [77]. A recent study of antibiotics and immunotherapy suggests that the use of antibiotics can affect the outcome of immunotherapy in patients [78]. The results showed that the median overall survival of all immunotreated patients was 14.6 months, including a median survival of up to 26 months for those who did not receive broad-spectrum antibiotics within 30 days of immunotherapy [78]. Even more surprising, a subset of patients who received broad-spectrum antibiotics during immunotherapy had a median overall survival of only 2 months. This may occur because antibiotics, when used in combination with immunotherapy, can produce direct immunotoxicity, genotoxicity or cytotoxicity by disrupting the intestinal microbiota, which can inhibit the immunotherapy for cancer [78].

In addition, antibiotics can also affect the therapeutic effect of immunocheckpoint inhibitors by causing intestinal flora disorder in the course of immunotherapy. In 2008, Bertrand Routy showed in an article that the richness of some intestinal flora could promote the anti-tumor effect of the immunocheckpoint inhibitors represented by PD-1 / PD-L1 and CTLA-4 [79]. However, antibiotic therapy significantly reduced the anti-tumor effect and survival time of mice treated with PD-1 monoclonal antibody alone or combined with CTLA-4 monoclonal antibody by mediating intestinal flora disorder [79]. Moreover, multiple courses or long-term use of antibiotics had a greater impact on the efficacy of checkpoint inhibitor therapy than short-term use of antibiotics [79]. Therefore, the side effects of anticancer antibiotics in immunotherapy should not be ignored.

\section{Summary of Primary Beneficial Effects of Cancer Treatment with Antibiotics}

Nowadays, antibiotics have been widely recognized in the treatment of cancers. When antibiotics are compared with traditional cancer treatments, such as surgery, radiotherapy, chemotherapy, immunotherapy and targeted therapy, the main performance is to improve the prognosis and reduce the side effects of antibiotics. And the brief description of this is as follows.

In the process of surgical treatment of cancer, although some cancers appear to be limited, but there are already cancer cells into the blood circulation, surgery can only cut out the local cancer, but not the cancer cells which have spread to the blood circulation. As a result, cancer surgery may often be followed by systemic drug therapy with antibiotics to remove the cancer and minimize the risk of recurrence.

Similarly, chemoradiotherapy reduce the number of cancer cells to achieve the therapeutic effect. However, after radiotherapy, most of the cancer patients will relapse after a period of time, which is also a difficult problem to be resolved in the current research of cancer biology, the main reason being the presence of CSCs [80]. With the traditional treatment of cancer, most of the cancer cells are eliminated, but if a small percentage of the total number of CSCs are still present, the recurrence of the cancer will occur even after most of the other cancer cells have been eliminated [80]. Thus, eradicating cancer requires eliminating CSCs first. Many studies have shown that the use of anticancer antibiotics can kill cancer stem cells in a special way through highthroughput screening, which has a high inhibitory effect on cancer recurrence, and thus successfully reduce the recurrence rate of cancer [52].

The proliferation rate of cancer cells is usually higher than that of the normal cells from which they came [81]. Fast-growing cancers (such as acute leukemia and choriocarcinoma) which have high rates of proliferation, are sensitive to anticancer drugs and can even be cured with chemotherapy [81]. One major problem, however, is that the cells lack physical space and nutrients due to competition, so cancer cells typically slow down. Slow-growing cancers, such as most solid cancers, including liver, lung, and stomach cancers, have low proliferation rates, low drug sensitivity, and poor efficacy [81, 82]. Even for cancers with high proliferation rates, G0 cells are rare, so after conventional anticancer drugs kill the proliferating cells, the G0 cells can proliferate again. Anticancer antibiotic is a new type of anticancer chemotherapy drug. Current studies have shown that the anticancer antibiotic is CCNSC, which can kill cells in the entire proliferation cycle, including G0 stage cells, and further enhance the sensitivity of cancer cells to fight against cancer antibiotics, so as to achieve the effect of inhibiting cancer cells more effectively [20].

Immunotherapy is currently a popular way to 
treat cancers, and its effective time is about 3 months, so the earlier the intervention, the better. At this point, adjuvant antibiotics can improve the immune function of the body, launch an attack on cancer, improve the overall situation, improve the treatment effect, and effectively prevent the recurrence and metastasis of cancer [83]. However, once the terminal stage of cancer is reached, the immune function of the patient is too low, and the immunotherapy is slow to take effect, and the therapeutic effect is often poor. So, the combination of immunotherapy and antibiotics is getting more and more attention. Compared with immunotherapy alone, the efficacy of antibiotics combined with it was better [83].

The clinical application of targeted drugs has indeed brought good news to patients with terminal diseases, at least improving the quality of life of patients and extending the survival period. But current "targeted drugs" are expensive and need to be taken every day. And it should be taken for more than one month. If it is effective, it should be taken orally for a long time until the drug is resistant, which causes a great burden on the patient's family. Moreover, targeted therapy does not have the effect of radical cure and is not effective for all cancers and all patients, which is also its great disadvantage.

\section{Summry of Primary Adverse Effects of Antibiotics}

During the use of antibiotic, bacteria are increasingly resistant to it, so the disadvantages of antibiotic treatment are also slowly becoming apparent [84]. Antibiotic resistance can be inherent or acquired through the process of gene mutation or gene transfer. Genetic information encoding these mechanisms can appear through random spontaneous mutations or can be transmitted through genes [84]. According to many researches, it is divided into 5 categories: the modification or destruction of antibiotics by enzymes; reduction in the intake of antibiotics into bacteria; increase of antibiotics from bacteria active outward excretion; changes in the target or the creation of new targets and overexpression of drug targets [85-87]. Therefore, the resistance of other microorganisms to mutations in the presence of certain antibiotics is more easily selected, and the use of the antibiotics should be carefully managed (Figure 3 ).

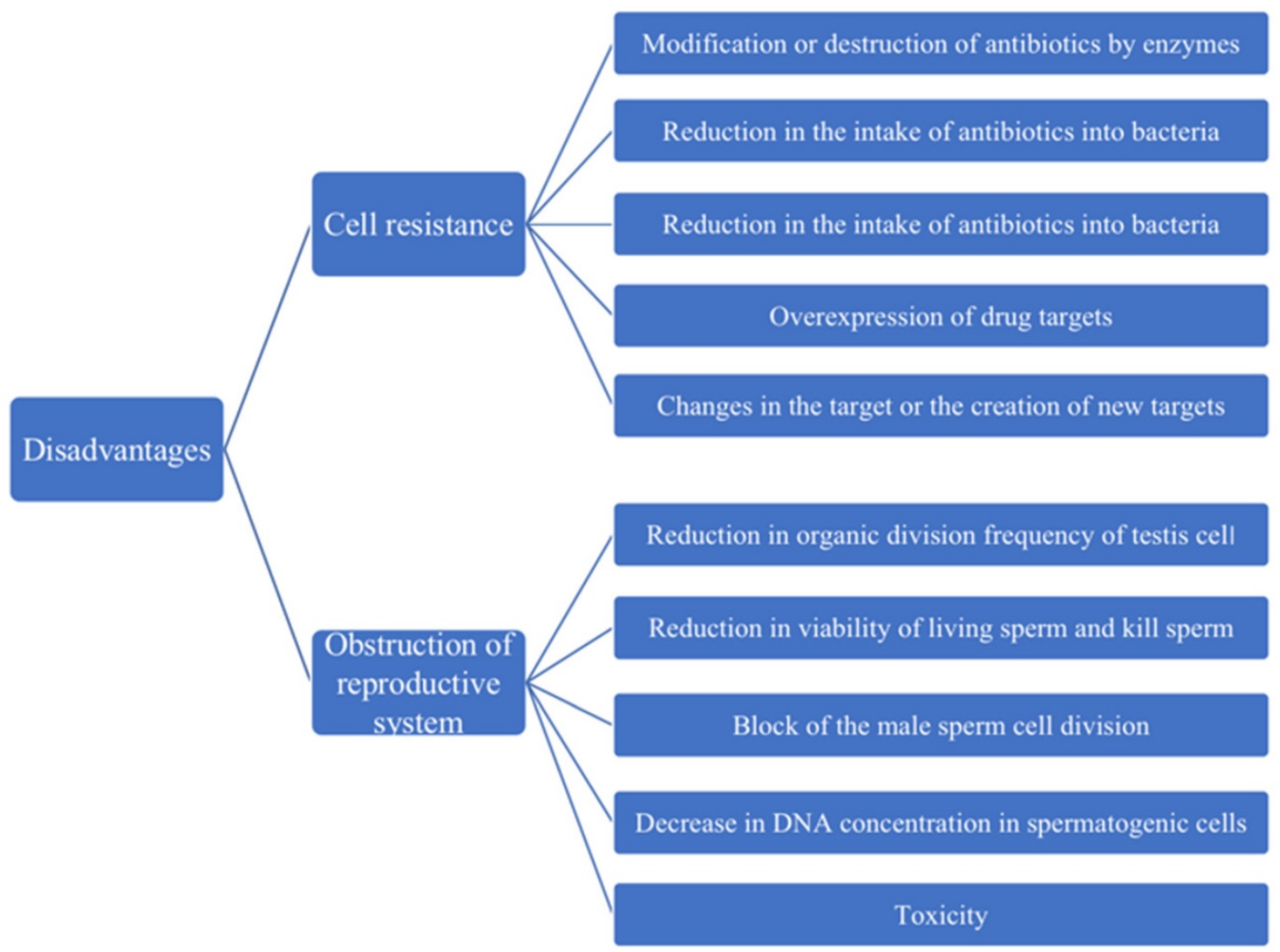

Figure 3. The disadvantages of antibiotics in the treatment of diseases. The major aspects of disadvantages are cell resistance and obstruction of reproductive system. 
In addition to developing antibiotic resistance to bacteria, frequent use of antibiotics can also lead to male infertility by decimating a man's sperm, greatly reducing his fertility (Figure 3 ). The impact of these antibiotics on the reproductive system has been questioned by experts for years. In 1995, e. d. Gol 'dberg, administered a single dose of the anthracyclines antibiotic pharmorubicin at the maximum permissible dose in an experiment, found destructive testicular changes and spermatogenic disorders in Wistar rats one to three months later. Moreover, one month after injection, the number of major lethal mutations increased, indicating that the anthracycline antibiotic panerythromycin had a delayed toxic effect on the morphological and functional status of the reproductive system and the genetic apparatus of the sex cells in male rats [88]. With the widespread use of antibiotics, the harm of antibiotics to the reproductive system is becoming more and more obvious; in particular, the influence on male reproductive ability cannot be ignored. Studies have shown that macrolidene antibiotics (such as erythromycin, spiramycin, medemycin, etc.) could reduce the organic division frequency of testicular cells, kill sperm, and significantly reduced the viability of living sperm [89]. In 2007, McClusky LM found that the use of gentamicin in large quantities could make the male sperm cell division blocked, the DNA concentration in spermatogenic cells decreased, resulting in the spermatogenic process to stop [90]. Similarly, Morice Philippe in 2007 found that there would be fertility in women after cancer treatment because tetracycline drugs are toxic to the gonads [91]. These experimental results showed in Figure 3 that antibiotics were not only destructive to male reproductive system, but also harmful to female reproductive system, which was also a problem that cannot be ignored for us.

Therefore, we can regulate the use of antibiotics in order to reduce the resistance of bacteria. If infection occurs, the type of bacteria causing the infection should be identified as soon as possible, and the number of combinations of drugs should be reduced as far as possible. At the same time, patients should be actively urged to take medicine according to the prescribed dosage and course of treatment.

\section{Future Directions}

Antibiotics play key role in the treatment of diseases, helping human beings to reduce the mortality rate of various infections, and significantly improving people's quality of life and life expectancy [92]. Moreover, antibiotics have been widely used as adjuvant drugs in the process of surgical treatment, radiotherapy, chemotherapy and immunotherapy of cancers due to their anti-infection and anticancer effects [93]. However, antibiotic resistance and its harm to the reproductive system are of increasing concern. At the same time, antibiotics can also reduce the effectiveness of surgery, radiation, chemotherapy and immunotherapy in combination, via leading the disorder of intestinal microbiota [60, 62].

In our previous studies, orally taking of probiotics drugs during radiotherapy, chemotherapy and surgery in patients can significantly reduce their side effects by improving the disorder of intestinal microbiota [94, 95]. Other works also indicated that dietary supplements (prebiotics) [96] or prebiotics [97] could selectively stimulate the growth and activity of internal probiotics to reduce the disorder of intestinal microbiota. As we known, probiotics in the intestinal tract (such as Bifidobacterium and Lactobacillus, etc.) are an indispensable element of human health and play a certain protective role in the intestinal tract [98], and the decrease of probiotics was the direct reason for intestinal microbial disorder [98]. Considering that the pro-cancer effects of antibiotics are mainly caused by their negative effect on intestinal microbiota, it is therefore a wise choice to reduce the side effect of antibiotics in cancer treatments via taking probiotics and prebiotics.

\section{Acknowledgements}

This work was supported by grants from the Science and Technology Project of Jiangxi (20194BCJ22032, 20181BBG700 [28] and 20181BCB24003 to Tingtao Chen).

\section{Authors' Contributions}

TC and YM designed the review; YG, QS, WL, WG and CM searched the materials; TC, YG and YM analyzed the references and wrote the manuscript. All authors discussed the results and commented on the manuscript.

\section{Competing Interests}

The authors have declared that no competing interest exists.

\section{References}

1. Rajaraman R, Guernsey DL, Rajaraman MM, Rajaraman SR. Stem cells, senescence, neosis and self-renewal in cancer. Cancer Cell Int. 2006;6:25.

2. Kanady K E SWU, Zietman A L, et al. Treatment strategies using transurethral surgery, chemotherapy, and radiation therapy with selection that safely allows bladder conservation for invasive bladder cancer[J]. 2015;13(5):359-64.

3. Lordick F HU. Chemotherapy and Targeted Therapy[J]. Medical Radiology. 2014.

4. Barrios-González J, Mejýa A. Production of Antibiotics and other Commercially Valuable Secondary Metabolites: Springer New York; 2008.

5. Xia D, et al. Over-expression of CHAF1A in Epithelial Ovarian Cancer can promote cell proliferation and inhibit cell apoptosis[J]. Biochemical \& Biophysical Research Communications. 2017;486(1):191-7.

6. Reuter G. The Lactobacillus and Bifidobacterium microflora of the human intestine: Composition and succession[J]. Curr Issues Intest Microbiol. 2001 ;2:43-53. 
7. Hernández DL. Letter to the Editor: Use of Antibiotics, Gut Microbiota, and Risk of Type 2 Diabetes: Epigenetics Regulation[J]. Journal of Clinical Endocrinology \& Metabolism. 2016;101(5):L62-L63.

8. Besnier JM, Leport C. Effect of antibiotics on bacterial adherence to foreign material. Pathologie Biologie. 1990;38(4):243-8.

9. Saeidnia S. Anticancer Antibiotics[M]// New Approaches to Natural Anticancer Drugs. 2015.

10. M CG. Natural Products Drug Discovery and Development at the United States National Cancer Institute[J]. Puerto Rico health ences journal. 2002;21(2):97-111.

11. Cheng M, Rizwan A, Jiang L. Molecular Effects of Doxorubicin on Choline Metabolism in Breast Cancer[J]. Neoplasia. 2017;19(8):617-27.

12. Miladiyah I, Yuanita E, Satyo N, et al. Synergistic Effect of 1,3,6-Trihydroxy-4,5,7-Trichloroxanthone in Combination with Doxorubicin on B-Cell Lymphoma Cells and Its Mechanism of Action Through Molecular Docking. [J]. Curr Ther Res Clin Exp. 2020;92: 100576

13. Wang Y, Liu J, et al. Inhibition of tumor metastasis by targeted daunorubicin and dioscin codelivery liposomes modified with PFV for the treatment of non-small-cell lung cancer.[J]. Int J Nanomedicine. 2019;14:4071-90.

14. Al-Aamri HM, Irving $\mathrm{KH}$, et al. Time dependent response of daunorubicin on cytotoxicity, cell cycle and DNA repair in acute lymphoblastic leukaemia[J]. Bmc Cancer. 2019;19(1).

15. Maffezzini M. Re: Intravesical Bacillus Calmette-Guérin versus Mitomycin C for Ta and T1 Bladder Cancer. european urology. 2006;50(6):1371-0.

16. Aarts BM, Klompenhouwer EG, et al. Sequential intra-arterial infusion of 90Y-resin microspheres and mitomycin $\mathrm{C}$ in chemo refractory liver metastatic breast cancer patients: a single centre pilot study.[J]. Radiol Oncol. 2020;54:33-9.

17. Murray V, Chen J, Chung L. The Interaction of the Metallo-Glycopeptide Anti-Tumour Drug Bleomycin with DNA[J]. International Journal of Molecular Sciences. 2018;19(5).

18. Prouvot C, Golfier F , Massardier J. Efficacy and Safety of Second-Line 5-Day Dactinomycin in Case of Methotrexate Failure for Gestational Trophoblastic Neoplasia[J]. International Journal of Gynecological Cancer. 2018;1.

19. Rao KV, Cullen WP, Sobin BAJA, Chemotherapy. New antibiotic with antitumor properties. 1962;12:182-6.

20. Xiao Z, Sperl B, Ullrich A, et al. Metformin and salinomycin as the best combination for the eradication of NSCLC monolayer cells and their alveospheres (cancer stem cells) irrespective of EGFR, KRAS, EML4/ALK and LKB1 status[J]. Oncotarget. 2014;5(24)

21. Zhou J, Li P, Xue X, He S, Kuang Y, Zhao H, et al. Salinomycin induces apoptosis in cisplatin-resistant colorectal cancer cells by accumulation of reactive oxygen species. Toxicol Lett. 2013;222(2):139-45.

22. Sánchez-Tilló E, Fanlo L, Siles L. The EMT activator ZEB1 promotes tumor growth and determines differential response to chemotherapy in mantle cell lymphoma[J]. Cell Death \& Differentiation. 2014;21(2):247-57.

23. Pratheeshkumar P, Kuttan G. Oleanolic acid induces apoptosis by modulating p53, Bax, Bcl-2 and caspase-3 gene expression and regulates the activation of transcription factors and cytokine profile in B16F[J]. 2011;30(1):21-31.

24. Hayward R, Hydock D, Gibson N, Greufe S, Bredahl E, Parry T. Tissue retention of doxorubicin and its effects on cardiac, smooth, and skeletal muscle function. Journal of Physiology and Biochemistry. 2012;69(2):177-87.

25. Takemura G, Fujiwara H. Doxorubicin-Induced Cardiomyopathy: From the Cardiotoxic Mechanisms to Management. 2007;49(5):330-52

26. Tartakoff SS, Finan JM, Curtis EJ, Anchukaitis HM, Couture DJ, Glazier S. Investigations into the DNA-binding mode of doxorubicinone. Org Biomol Chem. 2019;17(7):1992-8

27. Rogojina A, Nitiss J. Topoisomerase II-mediated single strand DNA breaks are cytotoxic. 2008:68:774

28. Barlow JJ, Piver MS, Chuang JT , et al. Adriamycin and bleomycin, alone and in combination, in gynecologic cancers[J]. Cancer. 1973;32.

29. Bearson BL, Brunelle BW. Fluoroquinolone induction of phage-mediated gene transfer in multidrug-resistant Salmonella. International Journal of Antimicrobial Agents. 2015;46(2):201-4.

30. Dalhoff A, Shalit IJLID. Immunomodulatory effects of quinolones. 2003:3(6):359-71.

31. Zemelman R, Bello HB, Dominguez M, et al. Activity of imipenem, third-generation cephalosporins, aztreonam and ciprofloxacin against multi-resistant Gram-negative bacilli isolated from Chilean hospitals[J]. Journal of Antimicrobial Chemotherapy. 1993;32(3):413-9.

32. Peloquin CA, Cumbo TJ, Nix DE, Sands MF, Schentag JJ. Evaluation of intravenous ciprofloxacin in patients with nosocomial lower respiratory tract infections. Impact of plasma concentrations, organism, minimum inhibitory concentration, and clinical condition on bacterial eradication. 1989;149(10):2269-73

33. Beberok A, Wrzesniok D, Minecka A, Rok J, Delijewski M, Rzepka Z, et al. Ciprofloxacin-mediated induction of S-phase cell cycle arrest and apoptosis in COLO829 melanoma cells. Pharmacol Rep. 2018;70(1):6-13.

34. Beberok A, Wrzesniok D, Rok J, Rzepka Z, Respondek M, Buszman E. Ciprofloxacin triggers the apoptosis of human triple-negative breast cancer MDA-MB-231 cells via the p53/Bax/Bcl-2 signaling pathway. Int J Oncol. 2018.

35. Kloskowski T, Gurtowska N, Olkowska J, Nowak JM, Adamowicz J, Tworkiewicz J, et al. Ciprofloxacin is a potential topoisomerase II inhibitor for the treatment of NSCLC. Int J Oncol. 2012;41(6):1943-9.
36. Mohammed $\mathrm{HHH}$, Abd El-Hafeez AA, Abbas $\mathrm{SH}$ Abdelhafez E-SMN, Abuo-Rahma GE-DA. New antiproliferative 7-(4-(N-substituted carbamoylmethyl)piperazin-1-yl) derivatives of ciprofloxacin induce cell cycle arrest at G2/M phase. Bioorganic \& Medicinal Chemistry. 2016;24(19):4636-46.

37. van Hazel GA, Rubin J, Moertel CG. Treatment of metastatic carcinoid tumor with dactinomycin or dacarbazine[J]. Cancer Treatment Reports. 1983;67(6):583-5.

38. Bowman RV, Manning LS, et al. Interaction between dactinomycin and tumor necrosis factor in mesothelioma. Cachexia without oncoiysis[J]. Cancer. 1991;67(10):2495-500.

39. Bloomfield CD, Brunning RD, Theologides A, et al. Daunorubicin-Prednisone remission induction with hydroxyurea maintenance in acute nonlymphocytic leukemia[J]. Cancer. 1973;31(4):931-8.

40. Marco AD, Casazza AM, Dasdia T, et al. Changes of activity of daunorubicin, adriamycin and stereoisomers following the introduction or removal of hydroxyl groups in the amino sugar moiety[J]. Chemico-Biological Interactions. 1977;19(3):291-302.

41. Waters JS, Norman A, Cunningham D, et al. Long-term survival after epirubicin, cisplatin and fluorouracil for gastric cancer: results of a randomized trial[J]. British Journal of Cancer. 1999;80(1):269-72.

42. Appelbaum PC, Gillespie SH, Burley CJ, Tillotson GS. Antimicrobial selection for community-acquired lower respiratory tract infections in the 21st century: a review of gemifloxacin. Int J Antimicrob Agents. 2004;23(6):533-46.

43. Chen TC, Hsu YL, Tsai YC, Chang YW, Kuo PL, Chen YH. Gemifloxacin inhibits migration and invasion and induces mesenchymal-epithelial transition in human breast adenocarcinoma cells. J Mol Med (Berl). 2014;92(1):53-64.

44. Ruiz EC. The role of the Snail2 transcription factor in Twist1-induced EMT and metastasis[J]. . Dissertations \& Theses. 2011.

45. Dong CF, Wu Y, Yao J, et al. G9a interacts with SNAIL and is critical for SNAIL-mediated E-cadherin repression in human breast cancer[J]. Journal of Clinical Investigation. 2012;122(4):1469-86.

46. Dees $\mathrm{A}$, et al. Mitomycin $\mathrm{C}$ is an inactive drug in the third-line treatment of hormone and chemotherapy refractory breast cancer[J]. European journal of cancer \& clinical oncology. 1987;23(9):1343-7.

47. Tomasz M. The mitomycin bioreductive antitumor agents : Cross-linking and alkylation of DNA as the molecular basis of their activity. 1997;76.

48. Rockwell S, Kim SY. Cytotoxic potential of monoalkylation products between mitomycins and DNA: studies of decarbamoyl mitomycin C in wild-type and repair-deficient cell lines. 1995;7(1):39.

49. Fox K, et al. DNA sequence preferences for the anti-cancer drug mitoxanthrone and related anthraquinones revealed by DNase I footprinting[J]. FEBS Letters. 1986;202.

50. Thürlimann B, et al. Plicamycin and pamidronate in symptomatic tumor-related hypercalcemia: a prospective randomized crossover trial[J]. Annals of oncology : official journal of the European Society for Medical Oncology. 1992;3(8):619.

51. Miyazaki Y, Shibuya M, Sugawara H, Kawaguchi O, Hirose C, Nagatsu J, et al. Salinomycin, a new polyether antibiotic. 1974;27(11):814.

52. Xipell E, Martinez-Velez, N, Vera-Cano, B. ET-66 * ER-STRESS INDUCING DRUGS SENSITIZES GBM TO TEMOZOLOMIDE THROUGH DOWNREGULATION OF MGMT AND INDUCTION OF REGULATED NECROSIS[J]. Neuro-Oncology.16(suppl 5):v93-v.

53. Abhisek M, Mishra L, Li S. EMT, CTCs and CSCs in tumor relapse and drug-resistance[J]. Oncotarget. 2015;6(13):10697-711.

54. Gupta PB, Onder TT, Jiang G, Tao K, Kuperwasser C, Weinberg RA, et al. Identification of selective inhibitors of cancer stem cells by high-throughput screening. Cell. 2009;138(4):645-59.

55. Lee HG, Shin SJ, Chung HW, Kwon SH, Cha SD, Lee JE, et al. Salinomycin reduces stemness and induces apoptosis on human ovarian cancer stem cell. J Gynecol Oncol. 2017; [28](2):e14.

56. Parajuli B, et al. Salinomycin Induces Apoptosis via Death Receptor-5 Up-regulation in Cisplatin-resistant Ovarian Cancer Cells[J]. Anticancer research. 2013;33(4):1457-62.

57. Parajuli B, Lee HG, Kwon $\mathrm{SH}$, Cha SD, Shin SJ, Lee GH, et al. Salinomycin inhibits Akt/NF-kappaB and induces apoptosis in cisplatin resistant ovarian cancer cells. Cancer Epidemiol. 2013;37(4):512-7.

58. Sánchez-Tilló E, Fanlo L, Siles L, et al. The EMT activator ZEB1 promotes tumor growth and determines differential response to chemotherapy in mantle cell lymphoma[J]. Cell Death and Differentiation. 2014;21(2):247-57.

59. Fred S, Sarfo CJL, et al. Mycobacterium ulcerans DNA Not Detected in Faecal Samples from Buruli Ulcer Patients: Results of a Pilot Study[J]. Plos One. $2011 ; 6$.

60. Sommer F, Anderson J, et al. The resilience of the intestinal microbiota influences health and disease[J]. Nature Reviews Microbiology. 2017.

61. Xin $X$, et al. Intestinal microbiota:a potential target for the treatment of postmenopausal osteoporosis[J]. 2017;46.

62. Sullivan A, et al. Effect of antimicrobial agents on the ecological balance of human microflora.[J]. 2012;1(2):101-14.

63. Gennari L, Zucali R, et al. Surgical treatment of intestinal complications after radiotherapy and surgery for malignant lymphoma and carcinoma of the testis.[J]. 1979;65(5):625-33.

64. Kilkkinen A, Rissanen $\mathrm{H}$, Klaukka T, Pukkala E, Heliovaara M, Huovinen P, et al. Antibiotic use predicts an increased risk of cancer. Int J Cancer. 2008;123(9):2152-5. 
65. Boursi B, Haynes K, Mamtani R, Yang YX. Impact of antibiotic exposure on the risk of colorectal cancer. Pharmacoepidemiology and Drug Safety. 2015;24(5):534-42.

66. Grivennikov S, Karin E, Terzic J, Mucida D, Yu GY, Vallabhapurapu S, et al. IL-6 and Stat3 Are Required for Survival of Intestinal Epithelial Cells and Development of Colitis-Associated Cancer. Cancer Cell. 2009;15(2):103-13.

67. Kaur P, Hurwitz MD, Krishnan S. Combined Hyperthermia and Radiotherapy for the Treatment of Cancer[J]. Cancers. 2011;3(4):3799-823.

68. Adlercreutz H, Evolution N. Intestinal Microflora, and Prevention of Cancer: A Hypothesis[J]. Experimental Biology and Medicine. 1998;217(3):41-46.

69. Shapiro TA, Fahey JW, Wade KL, Stephenson KK, Talalay P. Human metabolism and excretion of cancer chemoprotective glucosinolates and isothiocyanates of cruciferous vegetables. 1998;7(12):1091-100.

70. Blagosklonny MV. How avastin potentiates chemotherapeutic drugs: Action and reaction in antiangiogenic therapy[J]. Cancer Biology \& Therapy. 2005;4(12):1307-10.

71. Patel RN, Attur MG, Dave MN, et al. A novel mechanism of action of chemically modified tetracyclines: Inhibition of COX-2-mediated prostaglandin E-2 production. 1999;163(6):3459-67.

72. Thong YJC, Immunology E. Inhibition of mitogen-induced human lymphocyte proliferative responses by tetracycline analogues. 1979;35.

73. Attur MG, Patel RN, Patel PD, Abramson SB, Amin AR. Tetracycline up-regulates COX-2 expression and prostaglandin E2 production independent of its effect on nitric oxide. 1999;162(6):3160-7.

74. Coussens LM, Werb ZJN. Inflammation and cancer. 2002;420(6917):860-7.

75. Yamaguchi Y. History of and novel developments in cancer immunotherapy Introduction to the special issue[J]. Gan to Kagaku Ryoho Cancer \& Chemotherapy. 2013;40(9):1136-9.

76. Kashida Y, Sasaki Y, et al. Mechanistic Study on Flumequine Hepatocarcinogenicity Focusing on DNA Damage in Mice. Toxicol Sci. 2002;69(2):317-21.

77. Itoh T, Mitsumori K, Kawaguchi S, Sasaki YF. Genotoxic potential of quinolone antimicrobials in the in vitro comet assay and micronucleus test. Mutat Res. 2006;603(2):135-44.

78. Kuczma MP, Ding ZC, Li T. The impact of antibiotic usage on the efficacy of chemoimmunotherapy is contingent on the source of tumor-reactive T cells[J]. Oncotarget. 2017;8[67].

79. Routy B, Chatelier EL, Derosa L, et al. Gut microbiome influences efficacy of PD-1-based immunotherapy against epithelial tumors.[J]. Science. 2018;359:91-97.

80. Juan J, et al. Enrichment of Cells with Cancer Stem Cell-Like Markers in Relapses of Chemoresistant Patients with Locally Advanced Head and Neck Squamous Cell Carcinoma[J]. Oncology. 2016;90(5).

81. Young CC, et al. Intrinsic antibiotic resistance and competition in fast- and slow-growing soybean rhizobia on a hybrid of Asian and US cultivars[J]. Biology \& Fertility of Soils. 1989;8(1):66-70.

82. Napoli M. Mammograms Find Slow-Growing Cancers[J]. Healthfacts. 2000(May).

83. Yin D, et al. Influence of MP infection on immunologic function in patients with chronic obstructive pulmonary disease[J]. Hunan yi ke da xue xue bao= Hunan yike daxue xuebao $=$ Bulletin of Hunan Medical University. 1998;23(5):479-82.

84. Cohen R. The need for prudent use of antibiotics and routine use of vaccines[J]. Clinical Microbiology \& Infection. 2009;15( Suppl 3):21-3.

85. Disney MD. Studying Modification of Aminoglycoside Antibiotics by Resistance-Causing Enzymes via Microarray[J]. 2012;808.

86. Andrew D, McEachran BRB, et al. Antibiotics, Bacteria, and Antibiotic Resistance Genes: Aerial Transport from Cattle Feed Yards via Particulate Matter[J]. Environmental Health Perspectives. 2015;123(4):337-43.

87. Dersch P, et al. Roles of Regulatory RNAs for Antibiotic Resistance in Bacteria and Their Potential Value as Novel Drug Targets[J]. Frontiers in Microbiology. 2017;8:803-.

88. Gol"Dberg ED, et al. Delayed damaging effects of anthracycline antibiotics on the reproductive system of rats[J]. 1996;121(1):50-52.

89. Zhou J, Chen Y, Cassidy R. Separation and determination of the macrolide antibiotics (erythromycin, spiramycin and oleandomycin) by capillary electrophoresis coupled with fast reductive voltammetric detection[J]. Electrophoresis. 2000;21(7):1349-53.

90. Mcclusky L, et al. Stage-Related Increase in the Proportion of Apoptotic Germ Cells and Altered Frequencies of Stages in the Spermatogenic Cycle Following Gestational, Lactational, and Direct Exposure of Male Rats to p-Nonylphenol[J].Toxicological ences(1). 2007;95(1).

91. Morice $P$, et al. Therapy Insight: fertility in women after cancer treatment[J]. Nature Clinical Practice Endocrinology \& Metabolism. 2007;3(12):819-26.

92. Artem'eva OA, et al. Dihydroquercetin, the bioactive substance, to be used against pathogenic microorganisms as an alternative to antibiotics[J]. 2015.

93. Daniel J. Booser GNH. Anthracycline Antibiotics in Cancer Therapy[J]. 1994;47(2):223-58.

94. Jiang C, Wang H, Xia C. A randomized, double-blind, placebo-controlled trial of probiotics to reduce the severity of oral mucositis induced by chemoradiotherapy for patients with nasopharyngeal carcinoma[J]. Cancer. 2019;125(7):1081-90.

95. Zheng $\mathrm{CH}$, Chen TT, et al. A randomised trial of probiotics to reduce severity of physiological and microbial disorders induced by partial gastrectomy for patients with gastric cancer [J]. journal of cancer. 2019;10(3):568.
96. Ogueke $\mathrm{CC}$, Owuamanam $\mathrm{CI}$, Thediohanma $\mathrm{NC}$, et al Probiotics and Prebiotics: Unfolding Prospects for Better Human Health[J]. Pakistan Journal of Nutrition. 2010; 9: 833-843.

97. Mitsuyama K, et al. Intestinal microflora as a therapeutic target in inflammatory bowel disease[J]. Journal of Gastroenterology. 2002;37(14):73-7.

98. Zhang JW, Du P, Yang BR. Preoperative Probiotics Decrease Postoperative Infectious Complications of Colorectal Cancer[J]. American Journal of the Medical Sciences. 2012;343(3):199-205. 